\title{
Parálisis de Bell y dolor facial asociados con infección por Toxocara sp
}

\author{
Arian Bachtiar, Herbert Auer y Josef Finsterer
}

\section{Bell's palsy and facial pain associated with toxocara infection}

Objectives: Toxocarosis involving cranial nerves is extremely rare and almost exclusively concerns the optic nerve. Toxocarosis involving the seventh cranial nerve has not been reported. Case report: A $33 y$ male developed left-sided Bell's palsy two days after left-sided otalgia 6y before. Despite extensive diagnostic work-up at that time the cause of Bell's palsy remained unknown. During the following years Bell's palsy slightly improved but retromandibular pain remained almost unchanged and he developed enlarged lymph nodes along the jugular veins, submandibularly, and in the trigonum caroticum. Re-evaluation 6y later revealed an increased titer of serum antibodies against Toxocara canis and a positive Westernblot for Toxocara canis ES-antigen. Despite absent eosinophilia in the serum, toxocarosis was diagnosed and a therapy with albendazole initiated, with benefit for retromandibular pain, but hardly for Bell's palsy or enlarged lymph nodes. CSF investigations after albendazole revealed a positive Westernblot for antibodies against toxocara but absent pleocytosis or eosinophilia, and negative PCR for Toxocara canis. Conclusions: Visceral larva migrans due to Toxocara canis may be associated with Bell's palsy, retromandibular pain, and lymphadenopathy. A causal relation between Bell's palsy and the helminthosis remains speculative. Adequate therapy years after onset of the infestation may be of limited benefit.

Key words: Parasitosis, cranial nerve, facial nerve palsy, atypical facial pain, headache, chronic infection, larva migrans, helminthiasis, albendazole.

Palabras clave: Parasitosis, nervio craneal, parálisis facial, cefalea, larva migrans, helmintiasis, albendazol.

\section{Introducción}

$\mathrm{E}$ 1 compromiso de nervios craneales por larva migrans de Toxocara canis es sumamante inusual y casi exclusivamente afecta al nervio óptico ${ }^{1}$. No ha sido descrita la afectación del séptimo nervio craneal asociada a larva migrans de T. canis.

\section{Caso clínico}

Varón de 33 años, tunesino, seronegativo para virus de inmunodeficiencia humana, que a los 26 años de edad experimentó un episodio de otalgia, seguido por una parálisis de Bell dos días más tarde. La evaluación otorrinolaringológica y la serología para herpes simplex, herpes zoster, adenovirus, citomegalovirus, virus coxsackie, enterovirus, influenza, coriomeningitis linfocitaria, sarampión, parotiditis, rubéola, virus de Epstein-Barr, ornitosis, Mycoplasma pneumoniae y Borellia burgdorferi (incluyendo ADN), fueron todas negativas. Se le efectuaron, en forma repetida, una TAC de alta resolución del hueso temporal y mastoides y una resonancia magnética (RM) de la articulación témporo-mandibular, sin hallazgos patológicos. En particular, no se detectó anomalías del canal auditivo profundo, de los nervios vestibulo-coclear ni del laberinto. Además, una planigrafía cervical fue normal. Los estudios de conducción de nervios faciales y registro del músculo orbicular oral revelaron un potencial de acción muscular de tan sólo $741 \mu \mathrm{V}$ ante la estimulación desde el lado izquierdo. La evaluación oftalmológica arrojó un lagoftalmo de $2 \mathrm{~mm}$ pero durante un cierre forzado de párpados, la córnea logró ser cubierta, por lo que se propuso efectuar una tarsorrafia temporal. Un ultrasonido cervical demostró exclusivamente un adenoma tiroideo, que se visualizó como una lesión fría en el cintigrama. Una TAC cervical arrojó un moderado crecimiento de ganglios en el triángulo carotídeo izquierdo, en ubicación infra-clavicular, sub-mandibular, sub-mentoniana y a lo largo de las venas yugulares internas bilaterales. En los años siguientes, la parálisis de Bell mejoró levemente pero el dolor se mantuvo oscilante sin modificarse su máxima intensidad, pese a una exhaustiva analgesia que incluyó analgésicos no esteroidales, tramadol, carbamazepina, terapia neural y acupuntura.

A la edad de 33 años, el paciente consultó nuevamente en el Departamento de Otorrinolaringología. Refería esta vez una intensificación de la parálisis de Bell y una fatiga extrema después de efectuar ejercicios en el trabajo. En el nuevo examen clínico se palparon adenopatías en la
Krankenanstalt Rudolfstiftung, Vienna, Austria.

Department of Otorhinolaryngology (AB).

Neurological Department (JF). Medical University of Vienna, Vienna.

Institute of Specific Prophylaxis and Tropical Medicine, Center of Pathophysiology, Infectiology and Immunology,

Department of Medical Parasitology (HA).

Recibido: 2 de diciembre de 2011 Aceptado: 27 de julio de 2012

\section{Correspondencia a:}

Josef Finsterer

fifigs1@yahoo.de 
nuca y retro-mandibulares sospechándose un síndrome estilo-hioideo. El examen neurológico comprobó un dolor en el origen del músculo esternocleidomastoideo, nódulos linfáticos aumentados de tamaño en el triángulo carotídeo y submandibular izquierdos y parálisis de Bell. No había eosinofilia en el hemograma. Una RM cervical no demostró mayores hallazgos patológicos. Se planteó como hipótesis un dolor facial atípico, neuralgia o una migraña, elevándose la dosis de gabapentina a $900 \mathrm{mg} /$ día sin respuesta favorable. Se propuso la realización de serología contra parásitos, una punción lumbar y una biopsia ganglionar pero el paciente consintió inicialmente sólo con la medición de anticuerpos contra Toxoplasma gondii, T. canis, Taenia solium, Echinococcus granulosus y Echinococcus multilocularis. En forma inesperada, el test de ELISA para anticuerpos de T. canis demostró un título de 70 UAK (normal: < 25 UAK). Como complemento, el Westernblot para antígeno ES de T. canis fue positivo en el suero. Habiéndose diagnosticado una toxocarosis, se efectuó terapia con albendazol, $15 \mathrm{mg} /$ $\mathrm{kg}$ de peso $(800 \mathrm{mg} / \mathrm{d})$ durante tres semanas, esquema que fue repetido dos veces más adelante. Finalizando el primer ciclo de albendazol, el paciente refirió el cese temporal del dolor por primera vez en los últimos seis años. Además, los analgésicos no-esteroidales volvieron a ser efectivos. Después de finalizar la cura con albendazol, se le prescribió amoxicilina/ácido clavulánico para evitar la sobreinfección de los conductillos labrados por las larvas. No se detectó foco infeccioso de T. canis en el pulmón ni en el hígado.

En el seguimiento tras siete u ocho meses de la terapia con albendazol, las manifestaciones clínicas no habían cambiado mayormente pero el título de anticuerpos contra T. canis disminuyó a 25 UAK. En esta oportunidad, el paciente aceptó el procedimiento de punción lumbar pero persistió su rechazo a la biopsia ganglionar. El análisis citoquímico del LCR, habiéndose efectuado la terapia anti-parasitaria, fue normal, excepto por la positividad del antígeno ES de T. canis mediante Westernblot. No se detectó eosinofilia en el LCR, ni desviación Th2 en el sobrenadante $^{2}$, y hubo una RPC negativa para T. canis.

\section{Discusión}

La toxocarosis sistémica o síndrome de larva migrans es una helminto-zoonosis altamente prevalente, causada por la migración de las larvas del nemátodo $T$. canis a través de los tejidos humanos ${ }^{3}$. La población infantil es afectada con mayor frecuencia que los adultos ${ }^{3}$. La transmisión ocurre a través del contacto con perros, el consumo de carne o verduras crudas, jugar con tierra o por escasa higiene. En la mayoría de los casos, la toxocarosis es clínicamente inaparente. En casos puntuales, la toxocarosis puede manifestarse como un "síndrome de larva migrans visceral", un "síndrome de larva migrans ocular" (neuritis óptica), una "toxocarosis encubierta", o una toxocarosis “común"1,4,5. La neuropatía óptica por $T$. canis responde a la corticoterapia ${ }^{6}$. No se ha comunicado el compromiso de otros nervios craneales. La afectación del sistema nervioso central (SNC) es inusual ${ }^{2,7,8}$ y comprende la meningitis ${ }^{2,8,9}$, encefalitis ${ }^{8,10}$, mielitis , $^{2,7,9,10-13}, \mathrm{o}$ radiculitis ${ }^{8}$. Sin embargo, en modelos animales, larva migrans migra con frecuencia al $\mathrm{SNC}^{14}$.

Para explicar la relación entre toxocarosis y parálisis de Bell, pueden discutirse varias hipótesis. En primer lugar, que no haya relación causa-efecto entre la parálisis de Bell y la toxocarosis y esta segunda habría surgido con posterioridad a la primera; en este caso, la otalgia podría haber sido causada por otro agente, produciendo edema del nervio facial dentro del canal de Falopio, traduciéndose en una parálisis de larga duración, con una remisión espontánea parcial. Una segunda posibilidad es que la otalgia y la parálisis hubieran sido consecuencia de la migración de larva migrans a través del canal de Falopio o la mastoides, provocando edema y estrechamiento del canal de Falopio. En este caso, la infección parasitaria debió haber ocurrido seis años antes de su detección serológica. Tercera hipótesis es que la parálisis de Bell fuera una manifestación de una toxocarosis del SNC. Argumentos a favor de la relación causal entre la parálisis de Bell y la toxocarosis son que el dolor desapareció en forma transitoria en seguida tras el primer ciclo de albendazol, que la analgesia se hizo más eficiente tras el uso del antiparasitario, que la larva migrans no tratada permanece dentro del cuerpo por al menos seis años, que los anticuerpos anti-T. canis fueron positivos en el LCR, y que la toxocarosis crónica del SNC ha sido descrita previamente ${ }^{15,16}$. En contra de esta relación causal están que el paciente no tenía contacto cercano con perros, no consumía verduras crudas ni carne cruda, y, finalmente, que no tenía una eosinofilia significativa en el hemograma ni en el LCR. Argumentos para una toxocarosis cerebral en este paciente son la presencia de anticuerpos antitoxocara en el LCR, demostración del contacto entre larva migrans y el sistema inmune local ${ }^{17}$, y las adenopatías cervicales bilaterales. Es improbable una transmigración de anticuerpos anti-toxocara a través de la barrera hematoencefálica hacia el SNC, ya que no ha sido descrito con anterioridad. La ausencia de pleocitosis y eosinofilia en el LCR no excluye el diagnóstico de toxocarosis del SNC, particularmente tras tres ciclos de albendazol y el largo intervalo que medió entre la infección aguda y la determinación de anticuerpos. Además, imágenes repetidamente normales del SNC no descartan una toxocarosis de esta localización. Asumiendo una toxocarosis del SNC como la única causa de la parálisis de Bell, el segmento infundibular (intracerebral) del nervio debe haber estado 
comprometido, pero no queda claro por qué en tal caso sólo fue afectado un solo nervio craneal. La toxocarosis puede haber permanecido indetectable por el déficit leve y ausencia de manifestaciones sistémicas ("toxocarosis encubierta") ${ }^{4,11}$. Que albendazol no evidenciara mayor efecto sobre las adenopatías puede atribuirse a la cronicidad de las mismas. Limitaciones del estudio fueron la no medición de $\operatorname{IgE}$ en sangre y LCR, que el recuento diferencial de leucocitos en el hemograma al iniciarse la enfermedad no estuviera disponible, que la determinación de anticuerpos contra toxocara en el LCR no fuera efectuada en forma repetida y que no se buscaran huevos del helminto en las deposiciones.

Este caso muestra que la larva migrans visceral de $T$. canis puede estar asociada con parálisis de Bell, adenopatías locales, fatiga general y dolor retro-mandibular de larga duración. Acaso el test de Westernblot positivo en el LCR fue el resultado de una transmigración de anticuerpos séricos a través de la barrera hemato-encefálica o consecuencia de una genuina toxocarosis del SNC, continúa siendo materia de especulación.

\section{Resumen}

Objetivos: La toxocarosis que compromete los nervios craneales es extremadamente infrecuente y afecta casi exclusivamente al nervio óptico. No ha sido comunicada la toxocarosis que afecte al séptimo nervio cranial por lo que se expone un caso clínico. Caso clínico: Varón de 33 años que había presentado seis años antes, una otalgia izquierda seguida dos días más tarde de una parálisis de Bell ipsilateral. A pesar de un exhaustivo estudio, la causa de esta parálisis quedó sin etiología. En los años siguientes la parálisis mejoró moderadamente pero persistió un dolor retromandibular casi sin variaciones y el paciente desarrolló adenopatías en la cadena yugular, submandibulares y en el triángulo carotídeo. Una re-evaluación efectuada seis años más tarde detectó un título elevado de anticuerpos contra Toxocara canis y un antígeno ES de T. canis positivo mediante Westernblot. A pesar de no haber eosinofilia en la sangre, se diagnosticó una toxocarosis iniciándose terapia con albendazol, con lo cual se observó una reducción del dolor retro-mandibular aunque escaso beneficio sobre la parálisis de Bell y los ganglios comprometidos. El líquido cefalorraquídeo analizado después de haberse efectuado la cura con albendazol reveló un test de Westernblot positivo para anticuerpos anti-toxocara, en ausencia de pleocitosis o eosinofilia, y una RPC para Toxocara canis negativa. Conclusiones: El síndrome de larva migrans visceral debido a T. canis puede asociarse con parálisis de Bell, dolor retromandibular y linfoadenopatías. La relación causal entre la parálisis de Bell y la helmintosis permanece en el plano especulativo. La terapia anti-parasitaria realizada años tras la instalación de una infestación puede tener un beneficio aunque limitado.

\section{Referencias bibliográficas}

1.- Hayashi E, Akao N, Fujita K. Evidence for the involvement of the optic nerve as a migration route for larvae in ocular toxocariasis of Mongolian gerbils. J Helminthol 2003; 77: 313-5.

2.- Osoegawa M. Diagnosis and treatment of CNS parasite infection with special reference to parasitic myelitis. Rinsho Shinkeigaku 2004; 44: 961-4.

3.- García-Pedrique M E, Díaz-Suárez O, Estévez J, Cheng-Ng R, Araujo-Fernández M, Castellano J, et al. Prevalence of infection by Toxocara in schoolchildren in the community of El Mojan, Zulia state, Venezuela. Invest Clin 2004; 45: 347-54.

4.- Auer H, Aspöck H. Nosologie und epidemiologie der Toxocarose des menschendie aktuelle Situation in Österrreich. Wien Klin Wochenschr 2004; 116: 7-18.

5.- Trabelsi S, Belhadj S, Kallel K, Zouiten F, Ben Becheur S, Ben Ayed, et al. Toxocariasis: under-estimated disease. Report of 9 cases. Tunis Med 2004; 82: 684-9.

6.- Cox T A, Haskins G E, Gangitano J L,
Antonson D L. Bilateral Toxocara optic neuropathy. J Clin Neuroophthalmol 1983; 3: 267-74.

7.- Goffette S, Jeanjean A P, Duprez T P, Bigaignon G, Sindic, C J. Eosinophilic pleocytosis and myelitis related to Toxocara canis infection. Eur J Neurol 2000; 7: 703-6.

8.- Moreira-Silva S F, Rodrigues M G, Pimenta J L, Gomes C P, Freire L H, Pereira F E. Toxocariasis of the central nervous system: with report of two cases. Rev Soc Bras Med Trop 2004; 37: 169-74.

9.- Engel H, Spieckermann D A, Tismer R, Mobius W. Acute meningomyelitis due to Toxocara larvae. Dtsch Med Wochenschr 1971; 96: 1498.

10.- Ota S, Komiyama A, Johkura K, Hasegawa O, Kondo K. Eosinophilic meningo-encephalomyelitis due to Toxocara canis. Rinsho Shinkeigaku 1994; 34: 1148-52.

11.- Kawajiri M, Osoegawa M, Ohyagi Y, Ochi H, Furuya H, Nawa Y, et al. A case of myelitis caused by visceral larva migrans due to Ascaris suum presenting only with Lhermitte's sign. Rinsho Shinkeigaku 2001; 41: 310-3.

12.- Sellal F, Picard F, Mutschler V, Marescaux C,
Collard M, Magnaval J F. Myelitis caused by Toxocara canis (larva migrans). Revue Neurologique (Paris) 1992; 148: 53-5.

13.- Yoshida M, Shirao Y, Asai H, Nagase H, Nakamura H, Okazawa T, et al. A retrospective study of ocular toxocariasis in Japan: correlation with antibody prevalence and ophthalmological findings of patients with uveitis. J Helminthol 1999; 73: 357-61.

14.- Camparoto M L, Fulan B, Colli C M, Paludo M L, Falavigna-Guilherme A L, Fernández M A. Initial stage of development and migratory behavior of Toxocara canis larvae in BALB/c mouse experimental model. Genet Mol Res 2008; 7: 444-50.

15.- Scheid R, Tina Jentzsch R, Schroeter M L. Cognitive dysfunction, urinary retention, and a lesion in the thalamus-beware of possible toxocariasis of the central nervous system. Clin Neurol Neurosurg 2008; 110: 1054-7.

16.- Finsterer J, Auer H. Neurotoxocarosis. Rev Inst Med Trop Sao Paulo 2007; 49: 279-87.

17.- Hamilton C M, Brandes S, Holland C V, Pinelli E. Cytokine expression in the brains of Toxocara canis-infected mice. Parasite Immunol 2008; 30: 181-5. 